\title{
Effect of Spirulina platensis and Kelp algae on the content of thiamine and riboflavin in wheat bread
}

\section{Rosen Chochkov', Denka Zlateva², Dana Stefanova²}

\author{
1 - University of Food Technologies, Plovdiv, Bulgaria \\ 2 - University of Economics, Varna, Bulgaria
}

\section{Keywords:}

Bread

Spirulina platensis

Kelp

Thiamine

Riboflavin

Article history:

Received 22.07.2020

Received in revised form 01.11 .2020

Accepted 25.03.2021

Corresponding author:

Rosen Chochkov

E-mail:

rosen4o4kov@abv.bg

\section{Abstract}

Introduction. The purpose of the present study is to investigate the effect of some edible algae - Spirulina platensis and Kelp on the content of thiamine and riboflavin in wheat bread.

Materials and methods. Bread is obtained from wheat flour with the addition of Kelp and Spirulina platensis (powder) in the amount of 2 or $4 \%$ by the weight of flour. The vitamin content was evaluated by liquid chromatography with mass spectrometry (LC-MS) method.

Results and discussion. It was found that enrichment with Kelp and Spirulina platensis (in the amount of $2 \%$ and $4 \%$ by the weight of flour) leads to an increase in the content of thiamine and riboflavin in wheat bread. The two types of algae have different effects. The use of $2 \%$ Kelp leads to an increase of $7.35 \%$, and of $4 \%$ - by $28.27 \%$ of the amount compared to that in the control sample. The most significant increase being observed with the addition of $4 \%$ Spirulina platensis. The amount of thiamine is $1533.75 \mu \mathrm{g} / \mathrm{kg}$ of bread, which is almost twice as high as in the control sample.

The content of vitamin $\mathrm{B}_{2}$ in the control bread sample is $310.5 \mu \mathrm{g} / \mathrm{kg}$. When Kelp in the amount of $2 \%$ is added, the increase is by $81.7 \mu \mathrm{g} / \mathrm{kg}$, and at the higher dosage (4\%) the increase is by $120 \mu \mathrm{g} / \mathrm{kg}$ compared to the control sample and by $38.3 \mu \mathrm{g} / \mathrm{kg}$ compared to the bread with $2 \%$ algae. The highest value was reported for bread enriched with $4 \%$ Spirulina platensis. The riboflavin content is almost 3 times higher than in the control sample; 2.37 times higher than in the $2 \%$ Kelp sample and 2.16 times higher than in the $4 \%$ Kelp sample.

Conclusions. Fortification of wheat bread with some edible algae - Kelp and Spirulina platensis (especially in the amount of $4 \%$ by the weight of the flour) is an effective approach for increasing the content of thiamine and riboflavin. The effect of Spirulina platensis on the vitamin content is more pronounced. 


\section{Introduction}

The importance of vitamins for good health has long been known. Often, to ensure an adequate intake of vitamins, people (especially those on special diets for health reasons, vegetarians and vegans) consume foods fortified with vitamins derived from natural sources. Seaweed can be successfully used for this purpose. Honya et al. (1994) point out that fresh or dried seaweed is a traditional food of the diet in many coastal areas, especially on the Pacific coasts of Asia and South America. On the other hand, Boukid and Castellari (2021) outline a new trend - the use of algae in food formulation is positioning firmly in the food market in Europe. The number of food products containing algae has significantly increased during the period 2015-2019 (13,090 new food products containing algae were globally launched, of which 5720 - in Europe). However, most of the specific nutritional information on edible seaweeds concerns their protein content and favorable amino acid composition, but there are less researches on the vitamin content in micro- and macroalgae.

Fabregas and Herrero (1990) published results on vitamin content of various microalgal species. They noted that microalgae contained high concentration of provitamin A, vitamin $\mathrm{E}$, vitamin $\mathrm{B}_{1}$ and folic acid, compared to conventional food sources. They point out that Dunaliella tertiolecta is able to synthesize vitamin $\mathrm{B}_{12}$ (cobalamin), vitamin $\mathrm{B}_{2}$ (riboflavin), vitamin E (tocopherol) and provitamin A ( $\beta$-carotene). Pawlak et al. (2014) point out that seaweed containing vitamin $\mathrm{B}_{12}$ may be beneficial for people who follow a vegan diet who are at risk of vitamin $B_{12}$ deficiency (as it is found mainly in foods from animal origin). Because certain seaweeds are a valuable source of both fat- and water-soluble vitamins (Norziah and Ching, 2000) their use by the food industry and consumption by the general public is increasing. According to Kennedy (2016) seaweed is a good source of a number of water-soluble vitamins $\left(\mathrm{B}_{1}, \mathrm{~B}_{2}, \mathrm{~B}_{12}\right.$ etc.). Based on this, algae are of particular interest as food fortifiers due to the high content of biologically active ingredients (including vitamins). According to Kadam and Prabhasankar (2010), bakery products, which are the most widely consumed foods in the world, are best suited to include functional ingredients in the recipe to achieve good health, optimal duration and quality of human life. From this point of view, algae are a promising raw material for the bakery industry. Many authors study the influence of algae on the protein content (Achour et al., 2014), dietary fiber (Raman et al., 2019) and mineral content of wheat bread (Ak et al., 2016). Others pay attention to the effect of algae on the rheological properties of dough and bread (Rosell et al., 2001; Mamat et al., 2014), sensory properties and consumer acceptance of bread (Saharan and Jood, 2017), antioxidant activity (Różyło et al., 2017) and iodine content (Tsyganova et al., 2014). The effect of algae on the vitamin content of bread has been less studied.

Dulinski et al. (2018) conduct a study to design a functional rye bread enriched with algae extracts (Ascophyllum nodosum, Arthrospira platensis) and to analyze the content of its selected bioactive ingredients: phenolic acids and vitamins $\mathrm{B}_{1}$ and $\mathrm{B}_{2}$. As part of the research, an attempt was also made to estimate the absorbable pool of these compounds by using an in vitro procedure simulating digestion in the human digestive tract. It was found that the addition of algae at the stage of mixing the rye dough significantly contributed to the increase of the available pool of B vitamins in bread, especially riboflavin. The analysis shows that the tendency to increase the vitamin content applies to bread samples enriched with Arthrospira platensis. Relatively high in vitro bioavailability of vitamin $\mathrm{B}_{2}$ in bread was found (45-62\%). The authors attribute this to the beneficial effect of hydrocolloids present in its biomass on the absorption of bioactive ingredients. In the case of thiamine, such large increases in the content of this vitamin with the addition of the algae component were not observed, nevertheless the trends noted in the case of riboflavin were confirmed. 
There are relatively limited publications on the effects of different types of algae on the content of thiamine and riboflavin in bakery products. Both vitamins are sensitive to the influence of temperature, light and other factors which the cereal grains are subjected to. Technological processes in breadmaking can partially degrade these biocomponents in the range from $25 \%$ (thiamine) to even $50 \%$ (riboflavin) of their initial level in the raw material (Mihhalevski et al., 2013; Wolak et al., 2017). For this reason, many industrially produced grain products are fortified with B vitamins to restore their original levels. There is a significant gap in our knowledge about the effect of different types of seaweed on thiamine and riboflavin content of wheat bread.

Therefore, the purpose of the present study is to investigate the effect of Spirulina platensis and Kelp (in the amount of $2 \%$ and $4 \%$ by the weight of flour) on the content of thiamine and riboflavin in wheat bread.

\section{Materials and methods}

\section{Materials}

For the preparation of the bread samples, the following materials were used:

- Commercial wheat flour type 500 with the following properties: moisture content -12.8 $\%$; gluten content $-27.07 \%$; release of gluten $-6 \mathrm{~mm}$; titratable acidity $-2{ }^{\circ} \mathrm{H}$;

- Water - according to ISO 6107-1:2004;

- Commercial yeast (Lesafmaya);

- Salt - according to Codex Standard for Food Grade Salt CX STAN 150-1985;

- Spirulina platensis powder (average chemical composition: protein $64 \mathrm{~g} / 100 \mathrm{~g}$; fat 8.2 $\mathrm{g} / 100 \mathrm{~g}$ of which saturated $3.42 \mathrm{~g}$; carbohydrates $16.1 \mathrm{~g} / 100 \mathrm{~g}$, of which sugars $0.52 \mathrm{~g}$, fiber $7 \mathrm{~g} / 100 \mathrm{~g})$.

- Kelp powder (average chemical composition: protein $5.3 \mathrm{~g} / 100 \mathrm{~g}$; fat $4.2 \mathrm{~g} / 100 \mathrm{~g}$ of which saturated $0.9 \mathrm{~g}$; carbohydrates $12.0 \mathrm{~g} / 100 \mathrm{~g}$, of which sugars $0.5 \mathrm{~g}$, fiber $1.25 \mathrm{~g} / 100 \mathrm{~g}$ ).

\section{Methods}

\section{Dough and bread composition}

The composition of the bread samples is presented in Table 1.

Bread samples composition

\begin{tabular}{|l|c|c|c|c|c|}
\hline \multirow{2}{*}{ Ingredients } & \multicolumn{5}{|c|}{ Bread samples } \\
\cline { 2 - 6 } & $\begin{array}{c}\text { Control } \\
\text { sample }\end{array}$ & $\begin{array}{c}\text { Sample S2 - } \\
\text { with 2 \% } \\
\text { Spirulina } \\
\text { platensis }\end{array}$ & $\begin{array}{c}\text { Sample S4 - } \\
\text { with 4 \% } \\
\text { Spirulina } \\
\text { platensis }\end{array}$ & $\begin{array}{c}\text { Sample K2 - } \\
\text { with 2 \% } \\
\text { Kelp }\end{array}$ & $\begin{array}{c}\text { Sample K4 - } \\
\text { with 4 \% } \\
\text { Kelp }\end{array}$ \\
\hline Wheat flour, g & 250 & 245 & 240 & 245 & 240 \\
\hline Water, cm ${ }^{3}$ & 140 & 145 & 155 & 145 & 155 \\
\hline Yeast, g & 3.37 & 3.37 & 3.37 & 3.37 & 3.37 \\
\hline Salt, g & 3.25 & 3.25 & 3.25 & 3.25 & 3.25 \\
\hline S. platensis, g & - & 5 & 10 & - & - \\
\hline Kelp, g & - & - & - & 5 & 10 \\
\hline
\end{tabular}




\section{Bread preparation}

Bread is obtained from type 500 wheat flour by a two-phase method. Initially, knead the yeast, flour and water dough in a 1:1 ratio in kneading machine (Labomix 1000, Hungary). Pre-mixed Spirulina platensis and Kelp algae (powder) in the amount of $2 \%$ or $4 \%$ by the weight of flour are added to the mixing water (combinations $\mathrm{K} 2$ and $\mathrm{K} 4$, for the breads prepared with Kelp and combinations S2 and S4, for the breads prepared with Spirulina platensis, respectively). The control sample was prepared only with wheat flour. The dough thus prepared matures for 4 hours at $33^{\circ} \mathrm{C}$ and then mix the dough to obtain a homogeneous mass by adding the remainder of the flour according to the formulation and salt $(1.3 \mathrm{~kg} / 100$ $\mathrm{kg}$ flour). The bread dough divides $(440 \mathrm{~g})$ and forms, matures for 55 minutes at $38^{\circ} \mathrm{C}$ (Tecnopast CRN 45-12, Novacel ROVIMPEX Novaledo, Italy). After the final fermentation, the pieces of dough were put into an electric oven (Salva E-25, Spain) pre-heated to 200 $220^{\circ} \mathrm{C}$. The baking time is $24 \mathrm{~min}$, until the temperature in the center of the bread crumb reach $96-98^{\circ} \mathrm{C}$. After baking, the bread is allowed to cool down for $3 \mathrm{~h}$ at room temperature.

\section{Determination of vitamin $B_{1}$ and vitamin $B_{2}$ content}

Sample extraction. $5 \mathrm{~g}$ of each sample of bread were weighted into a $50 \mathrm{ml}$ centrifuge tube using an analytical balance. $25 \mathrm{ml}$ of doubly distilled water were added and the samples are dispersed with a Polytron apparatus for 10 minutes. The resulting suspensions were centrifuged at $4000 \mathrm{rpm}$ for 15 minutes. The upper layer was decanted into a centrifuge tube. The precipitate was dispersed twice more with $10 \mathrm{ml}$ of doubly distilled water. After each dispersion, the suspensions were centrifuged and the lower layers were combined, then filtered through a quantitative filter (syringe filter with a pore size of $0.45 \mu \mathrm{m}$ ). About $1 \mathrm{ml}$ was taken from the filtrate and stored at up to $4{ }^{\circ} \mathrm{C}$ for chromatographic analysis.

Analytical methods. In the samples thus prepared, the content of water-soluble vitamins $\mathrm{B}_{1}$ (thiamine) and $\mathrm{B}_{2}$ (riboflavin) was examined on a liquid chromatograph with a high-resolution mass-selective detector (LC-MS). The chromatographic system was equipped with M510 and M45 pumps (Waters Associates), Rheodyne M-7125 injector and scanning fluorescent detector. The mobile phase was methanol/water/acetic acid (31/68.5/0.5) containing $5 \mathrm{mM}$ sodium hexasulfonate. The determination of the chromatographic peaks was carried out by comparing the retention times of the pure substances for chemical analysis (certified reference material for vitamin $B_{1}$ and vitamin $B_{2}$ ) with that of the tested samples. The qualitative identification of the analytes was based not only on the retention times of each component, but also on the secondary mass spectrum of the characteristic result ions of the studied vitamins.

Data on the amount of vitamins tested in bread samples were processed by the integrated software of the liquid chromatograph with mass detector used.

\section{Results and discussion}

\section{Effect of Spirulina platensis and Kelp on the content of vitamin $\mathrm{B}_{1}$ in wheat bread}

The human body needs a minimum of $0.33 \mathrm{mg}$ of thiamine for every $1000 \mathrm{kcal}$ it consumes (Osiezagha et al., 2013). According to Harper (2006), many population groups worldwide suffer from vitamin $\mathrm{B}_{1}$ (thiamine) deficiency and are at risk of severe neurological diseases. Vitamin fortification of daily consumed foods (such as bread) is an effective and 
easily achievable measure to improve public health, thanks to which it can overcome their deficiency in all groups of the population.

Some authors (Batifoulier et al., 2006), aim to study by means of HPLC the content of vitamin $B_{1}$ in nine varieties of wheat, as well as in the flour and bread obtained from them. It has been found that vitamin $B_{1}$ content ranging from 2.60 to $6.13 \mu \mathrm{g} / \mathrm{g}$ dry matter in the different wheat varieties. This reveals that the vitamin content is genetically determined and should be an important factor to consider when selecting different varieties of wheat. After grinding, only $43 \%$ of thiamine present into low-ash flour (compared to $80 \%$ for wholemeal flour). After baking, the amount of thiamine decreases by $37 \%$ in white bread and by $31 \%$ into wholemeal bread.

It's well known that bread made from flours, which contain less particles from the peripheral layers of the grain, has a lower vitamin content. This is due to the fact that thiamine is unevenly distributed in the anatomical parts of the wheat grain - the aleurone layer and the germ are much richer in this vitamin than the endosperm. In addition, the high temperature effect during baking leads to the thermal destruction of a significant part of the vitamins. That is why wheat bread from flour type 500 is not a good source of vitamins for the human body. The effect of algae Spirulina platensis and Kelp on the content of vitamin $\mathrm{B}_{1}$ in wheat bread is presented in Figure 1.

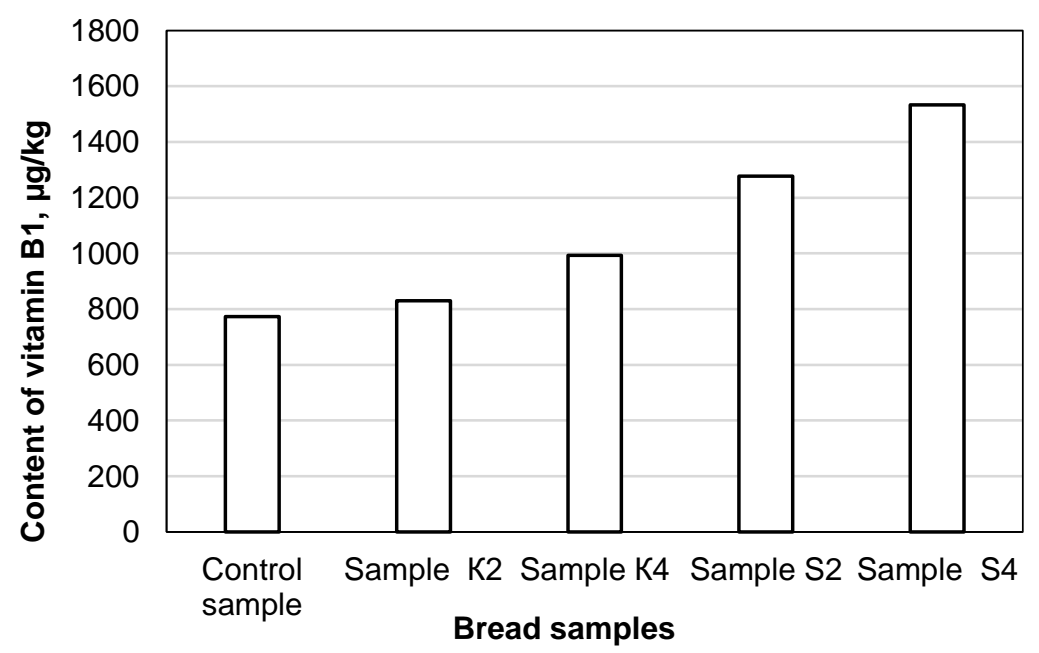

Figure 1. Effect of Kelp and Spirulina platensis algae on vitamin $B_{1}$ content in wheat bread.

The content of vitamin $B_{1}$ in wheat bread from flour type 500 is $773.75 \mu \mathrm{g} / \mathrm{kg}$. Our data on thiamine content are almost identical to those published by Tiong et al. (2015), which found an amount of $1.0 \pm 0.028 \mathrm{mg} / 100 \mathrm{~g}$ of product, but expressed the dry matter result (and the data presented by us are of fresh product). Other authors (Umelo et al., 2014) found lower amounts of vitamin $B_{1}$ in wheat bread - ranging from $0.034 \mathrm{mg} / 100 \mathrm{~g}$ to $0.044 \mathrm{mg} / 100 \mathrm{~g}$. In this case, both the genetic and varietal characteristics of the wheat and the specific technological parameters of bread preparation (such as the type and quantity of yeast, the duration of fermentation process) have an influence. 
From the data presented in Figure 1, it is clear that the addition of algae in the recipe of wheat bread leads to an increase in the content of vitamin $\mathrm{B}_{1}$. Both types of aquacultures affect the amount of thiamine to varying degrees. Kelp cause an increase in its content to a lesser extent. The use of $2 \%$ biomass from algae leads to an increase of $7.35 \%$, and of $4 \%-$ by $28.27 \%$ of the amount compared to that in the control sample. These results are expected, considering that brown algae contain relatively high amounts of thiamine. According to Sánchez-Machado et al. (2004) vitamin $B_{1}$ content vary from $0,14 \pm 0,02$ to $0,40 \pm 0,13 \mathrm{~g} / \mathrm{g}$ dry matter. Therefore, the replacement of a relatively small portion of wheat flour $(2 \%$ and $4 \%$ ) with these brown algae reflects this way on the content of vitamin $\mathrm{B}_{1}$ in bread.

When Spirulina platensis is added to the recipe of wheat bread, the effect on the amount of thiamine is much more pronounced. The addition of $2 \%$ caused an increase in the amount of vitamin $B_{1} 1.65$ times compared to the control sample. The reported result is $1277.5 \mu \mathrm{g} / \mathrm{kg}$ of bread. This amount is 1.54 times higher than in the sample enriched with $2 \%$ Kelp algae. When using $4 \%$ Spirulina platensis, the thiamine content is $256.25 \mu \mathrm{g} / \mathrm{kg}$ higher. The value obtained of $1533.75 \mu \mathrm{g} / \mathrm{kg}$ of bread is almost twice as high as for the control sample; 1.85 times higher than for the $2 \%$ Kelp sample and 1.55 times higher than for the $4 \%$ Kelp sample. The high efficiency of enrichment with these algae stems from the fact that they have a very high content of thiamine, which, however, shows strong seasonal variations. Babadzhanov et al. (2004) published the following data on thiamine content in Spirulina platensis: $11.6 \%$ of dry matter in biomass collected in winter; $15.4 \%$ in biomass collected in the spring; $0.8 \%$ in biomass collected during the autumn and summer seasons. According to these data the biomass grown in spring-summer had a high vitamin content. This shows a clear seasonal fluctuation in the vitamin content of algae. In order to increase the vitamin content of wheat bread, the biomass of Spirulina platensis, intended for enrichment, should be harvested during the spring-summer season. In addition, the amounts to enrich the bread and achieve adequate intake must be calculated according to the amount of thiamine in the biomass.

According to Yusuf et al. (2016) the thiamine content of Spirulina platensis ranges from 34 to $50 \mathrm{mg} / \mathrm{kg}$. There is a significant difference between the results published by the two authors. This is due to the fact that the composition of algae is not constant and varies depending on their species, geographical regions and harvesting season (Wells et al., 2017).

To get a better idea of the enrichment effect, a comparison was made between the recommended daily intake of thiamine and the extent to which the bread samples tested satisfies it.

The need to determine adequate vitamin $\mathrm{B}_{1}$ intake arose decades ago. As early as 1967, the World Health Organization set a recommended intake of thiamine $0.4 \mathrm{mg} / 1000 \mathrm{kcal}$. Therefore, an adult male consuming 3200-3300 kcal per day needs a daily intake of $1.3 \mathrm{mg}$ of thiamine, while a woman consuming an average of $2300 \mathrm{kcal}$ needs to take $0.9 \mathrm{mg}$ of thiamine per day. In 1989, the National Council for Research in the United States recommended a daily intake of $0.5 \mathrm{mg} / 1000 \mathrm{kcal}$ for adults, and the total daily intake not less than $1.0 \mathrm{mg}$ even for those consuming less than $2000 \mathrm{kcal}$ daily (World Health Organization, 1999).

In Bulgaria, Ordinance №1/2018 of the Ministry of Health differentiates the recommended thiamine intake depending on gender and age of the population. For men in the age range of 19 to 60 years, the recommended daily intake of thiamine is $1.2 \mathrm{mg}$, while for women of the same age $-1.0 \mathrm{mg}$. The degree to which the daily amount of bread consumed from the tested samples satisfies the recommended daily intake is presented in Figure 2. 


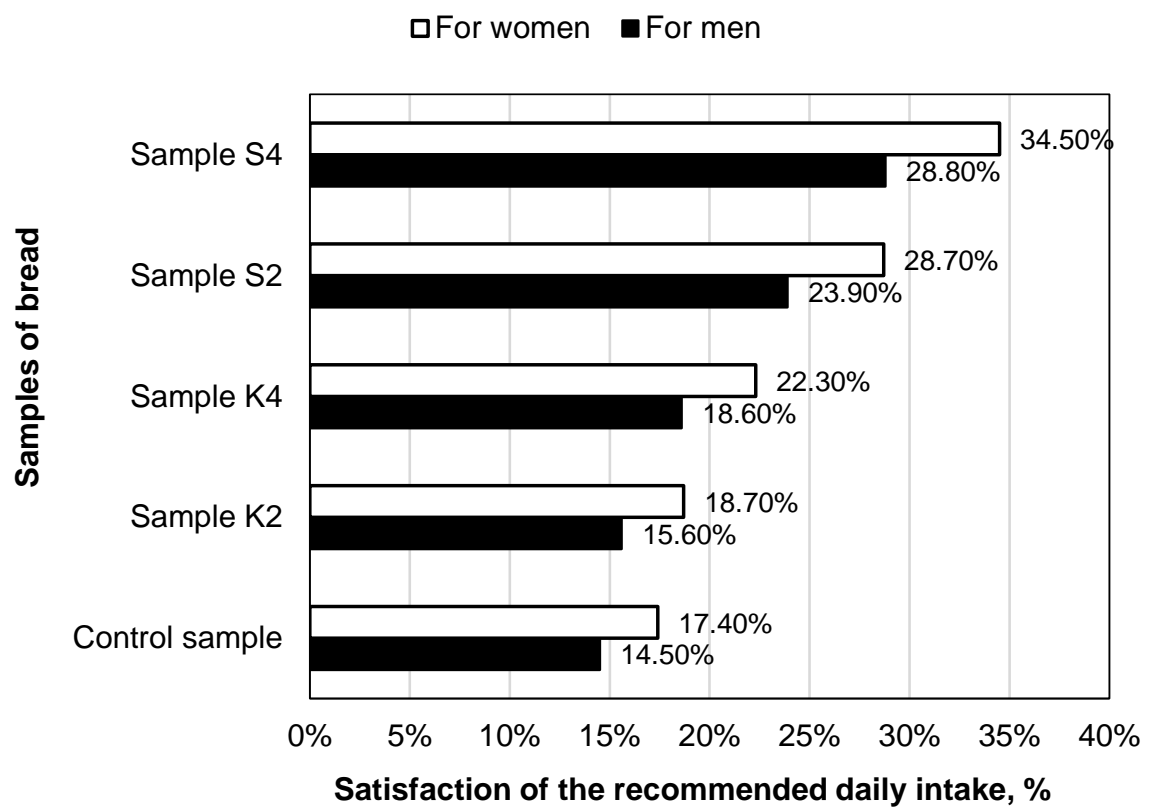

Figure 2. Effect of Kelp and Spirulina platensis on the degree of satisfaction of the recommended daily intake of vitamin $B_{1}$ in men and women aged 19 - 60 years

As can be seen from the figure, the average daily amount of wheat bread consumed in Bulgaria provides less than $15 \%$ of the adequate intake of thiamine for men and $17.40 \%$ of the adequate intake for women in the specified age range. We must take into account the fact that thiamine may not be properly absorbed by people who have liver problems; there are also some components in food that impair the absorption of thiamine (eg tannins in coffee and tea).

Enriching wheat bread with seaweed leads to a higher degree of satisfaction with adequate thiamine intake. The impact of both the type and the amount of aquaculture input is clear. Kelp algae have a less pronounced effect. When $4 \%$ of them are added to bread, its daily consumption provides $18.6 \%$ of the adequate intake of vitamin $\mathrm{B}_{1}$ for men and $22.3 \%$ of the adequate intake for women.

The impact of the other type of algae is more pronounced. Consumption of bread with $2 \%$ Spirulina platensis covers almost $24 \%$ of the recommended intake for men and almost $29 \%$ for women. If the amount of aquaculture is $4 \%$, the highest degree of satisfaction of the needed intake of vitamin $B_{1}$ is achieved. Consumption of the usual daily amount of bread provides $28.8 \%$ of the required amount for men and over a third $(34.5 \%)$ of the required amount for women aged 19 to 60 years. Replacing only $4 \%$ of wheat flour with Spirulina platensis makes bread twice as effective a source of thiamine for the human body (compared to the control sample).

For pregnant women and nursing mothers, a slightly higher adequate daily intake of thiamine was determined $-1.3 \mathrm{mg}$. Consumption of wheat bread provides $13.38 \%$ of this amount, and consumption of bread enriched with $4 \%$ Spirulina platensis $-26.5 \%$. 


\section{bread \\ Effect of algae Spirulina platensis and Kelp on the content of vitamin $B_{2}$ in wheat}

Riboflavin deficiency can cause vision problems, particularly cataracts. This disease is the result of abnormal aggregation of proteins in the lens, which causes it to become cloudy. In the elderly, the risk of cataract is increased due to riboflavin deficiency (Skalka and Prchal, 1981). Vitamin $B_{2}$ deficiency is found in about $80 \%$ of cataract patients. Riboflavin intake of $400 \mathrm{mg} /$ day has a preventive effect against the development of age-related cataracts (Buehler, 2011). People who adhere to a special diet due to health problems (diabetes, peptic ulcer disease, weight loss), as well as smokers, alcoholics and women using certain types of birth control (Škrovánková and Sikorová, 2010) are at increased risk of riboflavin deficiency.

Thus presented literature data show that insufficient intake of vitamin $B_{2}$ can affect health status in many different ways. The human body cannot synthesize this vitamin and therefore it must be absorbed through food through absorption in the small intestine. The results on the effect of Spirulina platensis and Kelp on the content of vitamin $\mathrm{B}_{2}$ in wheat bread are presented in Figure 3.

As can be seen from the figure, the content of vitamin $B_{2}$ in the control bread sample (from wheat flour type 500) is low $-310.5 \mu \mathrm{g} / \mathrm{kg}$. Similar results were published by MartinezVillaluenga et al. (2009). According to them the amount of vitamin $B_{2}$ in wheat bread is 45.48 $\pm 0.22 \mu \mathrm{g} / 100 \mathrm{~g}$ dry matter. If this value is recalculated for fresh product, it would mean $272.88 \mu \mathrm{g} / 100 \mathrm{~g}$. Regarding the content of vitamin $\mathrm{B}_{2}$ in bread, decisive factors are: its quantitative content in the flour, the duration of fermentation, $\mathrm{pH}$, high temperature exposure, exposure to ultraviolet radiation and others (Ahmad et al., 2004). Whole meal bread is a better source of this vitamin, as it is concentrated mainly in the germ and aleurone layer. The inclusion of Kelp seaweed in the bread recipe leads to an increase in the amount of riboflavin, but not very significantly. When the aquaculture is in the amount of $2 \%$, the increase is by $81.7 \mu \mathrm{g} / \mathrm{kg}$, and at the higher dosage (4\%) the increase is by $120 \mu \mathrm{g} / \mathrm{kg}$ compared to the control sample and by $38.3 \mu \mathrm{g} / \mathrm{kg}$ compared to the bread with $2 \%$ seaweed.

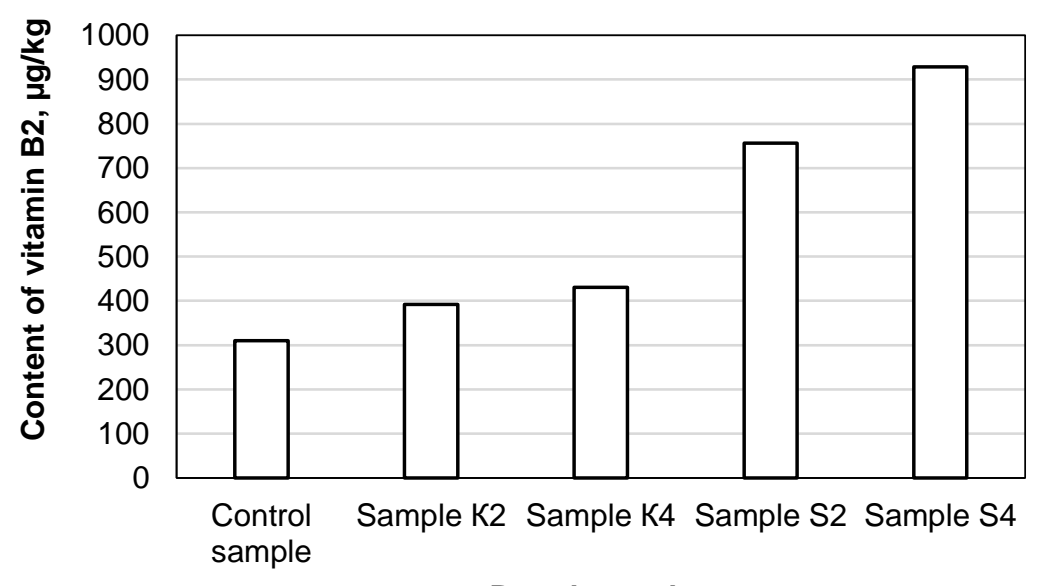

Bread samples

Figure 3. Effect of Kelp and Spirulina platensis algae on vitamin $\mathbf{B}_{2}$ content in wheat bread 


\section{Food Technology}

When Spirulina platensis is added to wheat bread, the effect on the amount of riboflavin is much more pronounced. In the sample with the addition of $2 \%$ of the algae content was reported 2.44 times higher than in the control sample and 1.93 times higher than in the bread with the same amount of Kelp. The highest value was reported for bread enriched with $4 \%$ Spirulina platensis. The riboflavin content is almost 3 times higher than in the control sample; 2.37 times higher than in the $2 \%$ Kelp sample; 2.16 times higher than in the $4 \%$ Kelp sample. If we compare the result with that for bread containing $2 \%$ Spirulina platensis - the increase is almost 23\%. This proves that enriching wheat bread with Spirulina platensis is effective and leads to a significant increase in vitamin $\mathrm{B}_{2}$ content.

Initially, the high protein content and favorable amino acid composition of algae aroused interest among researchers. Subsequently, it was found that they are a good source of other biologically active substances, including - vitamins (Wells et al., 2017). In fact, the literature on analytical methods and the content of riboflavin in biomass (fresh or dried) from Spirulina is contradictory. It has been reported that the content of riboflavin in Spirulina platensis varies from 37 to $45 \mu \mathrm{g} / \mathrm{g}$ dry matter (Andrade, 2018; Bishop and Zubeck, 2012). Edelmann et al. (2019) examined four varieties (different brands with different countries of origin) of Spirulina algae and found results ranging from 33.6 to $40.9 \mu \mathrm{g} / \mathrm{g}$ in the different samples. In the same publication, a comparison was made between the amount of riboflavin in the algae Spirulina platensis, Chlorella and $N$. gaditana powder. The author points out that of all the aquaculture studied, the best source of riboflavin is the algae Spirulina. This reveals the good potential for the use of Spirulina platensis as a supplement to increase the content of vitamin $B_{2}$ in wheat bread. A much lower content of riboflavin $(2-9 \mu \mathrm{g} / \mathrm{g})$ in Spirulina platensis has been reported by Babazhanov et al. (2004). Probably this is due to the variation in the amount of vitamins depending on the region and the water basin of aquaculture development, the season of their harvest and others.

Škrovánková and Sikorová (2010) point out that the recommended daily intake of riboflavin depends on protein and energy intake and varies from 1.2 to $1.7 \mathrm{mg}$ per day. According to Ordinance №1/2018 of the Ministry of Health in Bulgaria, the recommended intake of riboflavin for men in the age range from 19 to 60 years is $1.3 \mathrm{mg}$, while for women of the same age is $1.1 \mathrm{mg}$. The degree to which the daily amount of bread consumed from the various tested samples satisfies the recommended daily intake is presented in Figure 4.

As can be seen from the figure, the average daily amount of bread from the control sample provides a very small portion of the recommended intake - only $5.38 \%$ for men and $6.35 \%$ for women. If the diet includes other foods rich in riboflavin, this would compensate for its low content in bread. But for people for whom wheat bread has been a staple food for a long time, there is a risk of hypovitaminosis.

When Kelp is included in the bread recipe, the average daily amount of bread consumed covers the recommended intake to a higher degree. The impact of aquaculture is stronger when the amount is $4 \%$ by the weight of flour (respectively $7.45 \%$ of adequate intake for men and $8.80 \%$ of adequate intake for women).

The effect of algae Spirulina platensis is much more pronounced. If used in an amount of $2 \%$, the daily amount of bread consumed covers $13.10 \%$ of the adequate intake of riboflavin in men and $15.50 \%$ in women. These values are almost 2.5 times higher than those found in the control sample. To the greatest extent, the amount of thiamine obtained from bread is close to the recommended intake when $4 \%$ Spirulina platensis is included in the recipe. The daily intake of bread provides $16.1 \%$ of the required amount of riboflavin in men and almost one-fifth of the required amount in women. Thus enriched bread is three times more effective than the control sample and 2.16 times more effective than bread containing $4 \%$ Kelp in terms of meeting the recommended intake of vitamin $\mathrm{B}_{2}$. 


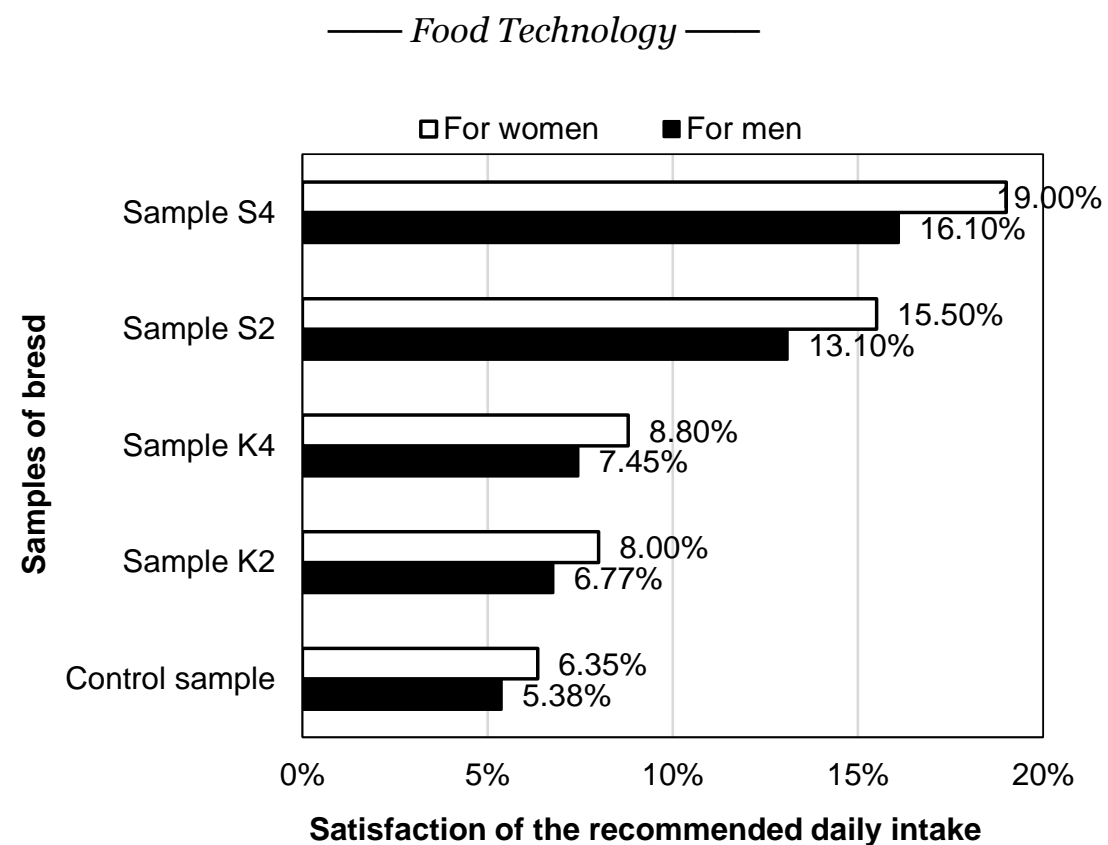

Figure 4. Effect of Kelp and Spirulina platensis on the degree of satisfaction of the recommended daily intake of vitamin $B 2$ in men and women aged $19-60$ years

For pregnant women, the recommended daily intake of this vitamin is $1.4 \mathrm{mg}$. The control sample of bread yields only $5 \%$ of this amount, and the bread with $4 \%$ Spirulina platensis $-14.9 \%$. The highest norms for daily requirement of vitamin $\mathrm{B}_{2}$ are set for women who are breastfeeding $-1.6 \mathrm{mg}$. In this case, wheat bread provides only $4.4 \%$ of the required amount of riboflavin, while fortified bread $-6 \%$ when using Kelp and 13\% when using Spirulina platensis (in the amount of $4 \%$ ).

\section{Conclusion}

1. From the results obtained in the present study, it was found that the fortification of wheat bread with Kelp and Spirulina platensis algae (in the amount of $2 \%$ and $4 \%$ by the weight of flour) is a good opportunity to increase the content of thiamine and riboflavin.

2. The effect of Spirulina platensis is more pronounced, as the highest values for both vitamins were found when adding $4 \%$ of the algae to the raw materials for bread making.

3. By including biomass of algae Kelp and Spirulina platensis in the bread recipe, a significantly higher degree of satisfaction of the recommended daily intake of thiamine and riboflavin is achieved. This approach would allow prevention of deficiency of these vitamins in some groups of the population and improvement of the health status.

These data show that enriching wheat bread with Kelp and Spirulina platensis is a successful approach to increasing the content of thiamine (vitamin $\mathrm{B}_{1}$ ) and riboflavin (vitamin $\mathrm{B}_{2}$ ) in bread. This way a large part of the population could achieve an intake of these vitamins, much closer to the adequate. 
Acknowledgements. Authors would like to thank to the Ministry of Education and Science of Bulgaria about the subsidy by Regulation № 3 from 27.11.2015 in accordance with the Ordinance on the Terms and Procedure for the Evaluation, Planning, Allocation and Expenses of the State Budget Funds for the Financing of the Inherent Research Activities of the State Higher Education Institutions. The acknowledgements are also to the academic management of University of Economics - Varna for the allocations in project NPI-16/2018 "Innovative approaches to increase the quality and biological value of foods".

\section{References}

Achour H., Doumandji A., Sadi S., Saadi S. (2014), Evaluation of nutritional and sensory properties of bread enriched with spirulina, Annals Food Science and Technology, 15 (2), pp. 270 275.

Ahmad I., Fasihullah Q., Noor A., Ansari I., Manzar Ali Q. (2004), Photolysis of riboflavin in aqueous solution: a kinetic study, International Journal of Pharmaceutics, 280(1-2), pp. 199208.

Ak B., Avşaroğlu E., Işık O., Özyurt G., Kafkas E., Etyemez M., Uslu L. (2016), Nutritional and physicochemical characteristics of bread enriched with microalgae spirulina platensis, International Journal of Engineering Research and Application, 6 (12), pp. 30-38.

Andrade L. (2018), Chlorella and Spirulina microalgae as sources of functional foods, nutraceuticals, and food supplements; an overview, MOJ Food Process.Technol., 6, pp. 00144.

Babadzhanov A., Abdusamatova N., Yusupova F., Faizullaeva N., Mezhlumyan L., Malikova M. (2004), Chemical composition of Spirulina platensis cultivated in Uzbekistan, Chemistry of Natural Compounds, 40(3), pp. 276-279.

Batifoulier F., Verny M.-A., Chanliaud E., Rémésy C., Demigné C. (2006), Variability of B vitamin concentrations in wheat grain, milling fractions and bread products, European Journal of Agronomy, 25(2), pp. 163-169.

Bishop M., Zubeck H. (2012), Evaluation of Microalgae for use as nutraceuticals and nutritional supplements, J. Nutr. Food Sci., 2, pp. 147.

Boukid F., Castellari M. (2021), Food and beverages containing algae and derived ingredients launched in the market from 2015 to 2019: a front-of-pack labeling perspective with a special focus on Spain, Foods, 10, pp. 173.

Buehler B. (2011), Vitamin B2: Riboflavin, J. Evid. Based. Complementary Altern. Med., 16, pp. 88-90.

Duliński R., Byczyński L., Karbowski A. (2018), Określenie zawartości wybranych kwasów fenolowych i witamin z grupy b w pieczywie żytnim wzbogaconym $\mathrm{w}$ algi oraz oszacowanie biodostępności tych związków in vitro, ŻYWNOŚĆ. Nauka. Technologia. Jakość, 25, 3 (116), pp. $58-70$.

Edelmann M., Aalto S., Chamlagain B., Kariluoto S., Piironen V. (2019), Riboflavin, niacin, folate and vitamin $\mathrm{B}_{12}$ in commercial microalgae powders, Journal of Food Composition and Analysis, 82, pp. 103226.

Fabregas J., Herrero C. (1990), Vitamin content of four marine microalgae. Potential use as source of vitamins in nutrition, J. Ind. Microbiol., 5, pp. 259-263.

Harper C. (2006), Thiamine (vitamin B1) deficiency and associated brain damage is still common throughout the world and prevention is simple and safe, Eur J Neurology, 13, pp. 10781082 . 
Honya M., Kinoshita T., Ishikawa M., Mori H., Nisizawa K. (1994), Seasonal varation in the lipid content of cultured Laminaria japonica: fatty acids, sterols, $\beta$-carotene and tocopherol, J. Appl. Phycol., 6, pp. $25-29$.

Kadam S., Prabhasankar P. (2010), Marine foods as functional ingredients in bakery and pasta products, Food Research International, 43 (8). pp. 1975-1980.

Kennedy D. (2016), B Vitamins and the brain: Mechanisms, dose and efficacy-A review, Nutrients, 8 (2). pp. 68.

Mamat H., Matanjun P., Ibrahim S., Amin S., Hamid M., Rameli A. (2014), The effect of seaweed composite flour on the textural properties of dough and bread, Journal of Applied Phycology, 26, pp. 1057-1062.

Martinez-Villaluenga C., Horszwald A., Frias J., Piskula M., Vidal-Valverde C., Zielinski H. (2009), Effect of flour extraction rate and baking process on vitamin $B_{1}$ and $B_{2}$ contents and antioxidant activity of ginger-based products, European Food Research and Technology, 230, pp. $119-124$.

Mihhalevski A., Nisamedtinov I., Hälvin K., Ošeka A., Paalme T. (2013) Stability of Bcomplex vitamins and dietary fiber during rye sourdough bread production. J. Cereal Sci., 57 (1), pp. 30-38.

Norziah M., Ching Ch. (2000), Nutritional composition of edible seaweed Gracilaria changgi, Food Chem., 68, pp. 69-76.

Osiezagha K., Ali S., Freeman C., Barker N., Jabeen S., Maitra S., Olagbemiro Y., Richie W., Bailey R. (2013), Thiamine Deficiency and Delirium, Innov Clin Neurosci, 10(4), pp. 26-32.

Pawlak R., Lester S. Babatunde T. (2014). The prevalence of cobalamin deficiency among vegetarians assessed by serum vitamin $\mathrm{B}_{12}$ : a review of literature. Eur J Clin Nutr. 68. pp. 541548.

Raman M., Dinakaran A., Ravindran A., Sankar T., Gopal T. (2019), Dietary supplementation of $\kappa$-carrageenan to improve the physio-chemical and functional properties of white bread, Food and Nutrition Sciences, 10, pp. 997-1010.

Rosell C., Rojas J., Benedito de Barber C. (2001), Influence of hydrocolloids on dough rheology and bread quality, Food Hydrocoll, 15, pp. 75-81.

Różyło R., Hassoon W., Gawlik-Dziki U., Siastała M., Dziki D. (2017), Study on the physical and antioxidant properties of gluten-free bread with brown algae, CyTA-Journal of Food, 15 (2), pp. 196-203.

Saharan V., Jood S. (2017), Vitamins, minerals, protein digestibility and antioxidant activity of bread enriched with Spirulina platensis powder, International Journal of Agriculture Sciences, 9 (9), pp. 3917-3919.

Sánchez-Machado D., López-Cervantes J., López-Hernández J., Paseiro-Losad P. (2004), Simultaneous Determination of Thiamine and Riboflavin in Edible Marine Seaweeds by HighPerformance Liquid Chromatography, Journal of Chromatographic Science, 42, pp. 117-120.

Skalka H., Prchal J. (1981), Cataracts and riboflavin deficiency, Am. J. Clin. Nutr., 34, pp. 861-863.

Škrovánková S., Sikorová P. (2010), Vitamin $\mathrm{B}_{2}$ (riboflavin) content in cereal products, Acta univ. agric. et silvic. Mendel. Brun., LVIII, 5, pp. 377-382.

Tiong S., Chandra-Hioe M., Arcot J. (2015), Thiamin fortification of bread-making flour: Retention in bread and levels in Australian commercial fortified bread varieties, Journal of Food Composition and Analysis, 38, pp. 27-31.

Tsyganova T., Semenkina N., Babin A., Prosvirina A., Dimitrenko Y. (2014), The use of crushed food Fucus in the production technology of bread from a mixture of rye and wheat flour, Bread baking in Russia, 2, pp. 23-25.

Umelo M., Nsofor A., Akajiaku L., Odimegwu E., Uzoukwu A., Agunwah I., Eluchie C., Alagbaoso S., Njoku N. (2014), Effect of different dough improvers on the proximate 
composition, minerals, vitamins and sensory properties of wheat bread, International Journal of Scientific Research and Innovative Technology, 1(3), pp. 112-126.

Wells M., Potin P., Craigie J., Raven J., Merchant S., Helliwell K., Smith A., Camire M., Brawley S. (2017), Algae as nutritional and functional food sources: revisiting our understanding, J. Appl. Phycol., 29, pp. 949-982.

Wolak N., Zawrotniak M., Gogól M., Kozik A., Rąpała-Kozik M. (2017), Vitamins B ${ }_{1}, B_{2}$, $\mathrm{B}_{3}$ and $\mathrm{B}_{9}$ : Occurrence, biosynthesis pathways and functions in human nutrition. Mini-Reviews Med. Chem., 17 (12), pp. 1075-1111.

Yusuf M., Hassan M., Abdel-Daim M., Nabtiti A., Ahmed A., Moawed S., El-Sayed A., Cui H. (2016), Value added by Spirulina platensis in two different diets on growth performance, gut microbiota, and meat quality of Japanese quails, Veterinary World, 9(11), pp. 1287-1293. 